\title{
The Formation of Cyclic Oligomers Accompanying the Polymerization of Oxetane
}

\author{
P. Dreyfuss \\ Institute of Polymer Science, The University of Akron, \\ Akron, Onio 44325, USA. \\ M. P. DReyfuss \\ Corporate Research, B.F. Goodrich Company, Research and Development \\ Center, Brecksville, Ohio 44141, USA.
}

(Received June 20, 1975)

\begin{abstract}
A systematic investigation of the factors that influence cyclic oligomer formation in the polymerizations of oxetane initiated by triethyloxonium salts or ethyl trifluoromethanesulfonate is reported. In addition to the cyclic tetramer and polymer, which were previously reported, cyclic trimer was unexpectedly found. No higher cyclic oligomers were observed. Cyclic oligomer formation is a concurrent process with polymerization and not the result of a backbiting reaction with depolymerization or termination. The amount and type of cyclic oligomer obtained is very dependent on counter-ion, temperature, and solvent. Polymerizations initiated by triethyloxonium tetrafluoroborate resulted in as much as $35-\%$ conversion to oligomer at complete conversion. Cyclic tetramer was predominant. Other oxonium salts $\left(\mathrm{PF}_{6}{ }^{-}, \mathrm{SbF}_{6}{ }^{-}\right.$, and $\mathrm{SbCl}_{6}{ }^{-}$) produced insignificant conversion to cyclic oligomers. Polymerizations initiated by ethyl trifluoromethanesulfonate led to as much as $15-\%$ cyclic oligomer, almost exclusively cyclic trimer. Below $50^{\circ} \mathrm{C}$ little oligomer was observed. Higher temperatures favored cyclic oligomer formation. The effect of solvent depended on the counterion and cyclic oligomer under consideration.

KEY WORDS Oxetane / Cyclic Trimer / Cyclic Tetramer / Cationic Polymerization / Cationic Oligomerization / Oxonium Salt Initiators /
\end{abstract}

The polymerization of cyclic ethers frequently, but strangely not always, gives not only polymer but also cyclic oligomers. ${ }^{1-6}$ The polymers are usually the desired products but since the discovery of the usefulness of crown ethers, ${ }^{7}$ interest in cyclic oligomers has increased greatly. Synthesis of crown ethers by many classical routes is cumbersome and expensive. ${ }^{7}$ Hence several more direct routes, one using a typical polymerization initiator, $\mathrm{HF}$ plus $\mathrm{BF}_{3}$, and another using $72 \%$ perchloric acid and acetic anhydride, have recently been proposed..$^{8,9}$ Yet it is not known whether polymerization conditions can be adjusted to give predominantly cyclic oligomers. No systematic investigation of the factors that influence cyclic oligomer formation in a cyclic-ether polymerization has been reported. The present study gives the results of the effect of temperature, counter-ion, and a few solvents on oligomer formation in a model polymerization, the polymerization of oxetane.

Oxetane was chosen for initial investigation because the work of Rose suggests that in addition to polymer the only other product is cyclic tetramer. ${ }^{1}$ Furthermore, Rose's work also indicates that at temperatures of $50^{\circ} \mathrm{C}$ or above quite significant amounts of tetramer, $35-40 \%$, were obtained.

\section{EXPERIMENTAL}

\section{Materials}

Oxetane (Columbia Organic Chemicals) was purified according to Saegusa. ${ }^{10}$ Solvents were dried and distilled by standard procedures. $n$ - 
Tetradecane was redistilled under vacuum. Initiators were prepared and purified as previously reported..$^{11-13}$

\section{Polymerizations}

Polymerizations were conducted under nitrogen in a closed round bottom flask fitted with a dual rubber seal (reinforced neoprene and butyl rubber). A $25-\%$ solution by volume $(3.8 \mathrm{M})$ of oxetane, usually in 1,2-dichloroethane (EDC) was charged. A typical charge contained 1.1-g oxetane, 4.5-g EDC and 0.1-g $n$-tetradecane. The polymerization mixture was stirred magnetically while heating in an oil bath to the desired temperature. Initiator solution $(0.1 \mathrm{~g} / \mathrm{m} l$ in EDC) was added incrementally using a 50microliter syringe until all the monomer had disappeared. Disappearance of monomer and appearance of cyclic oligomer was followed by sampling at appropriate intervals with a syringe and injecting the solution into a gas chromatograph. $n$-Tetradecane ( $2 \%$ by weight) were used as internal standard. Monomer which had disappeared but could not be accounted for as cyclic oligomer was presumed to be polymer. At the end of each experiment the polymer was isolated by evaporation and dried in a vacuum oven at $60^{\circ} \mathrm{C}$. The amount of polymer obtained was consistent with the above assumption.

\section{Chromatography}

Gas chromatograms were obtained on a Hewlett-Packard Research Chromatograph using a six-foot 10-\% SE-30 column. A program heating from 70 to $240^{\circ} \mathrm{C}$ at $60^{\circ} \mathrm{C} / \mathrm{min}$ was found most suitable for separating the various components in the mixture.

Mass chromatograms were obtained on a Chemalytics MC-2 Mass Chromatograph using a heating rate of $10^{\circ} \mathrm{C} / \mathrm{min}$ from 25 to $250^{\circ} \mathrm{C}$. Sulfur hexafluoride and carbon dioxide were used as carrier gases.

\section{RESULTS}

\section{The Products}

A gas chromatogram from a typical reaction mixture is shown in Figure 1. Peaks A and B were due to monomer and solvent respectively. Peak E was identified as cyclic tetramer by comparison with an authentic sample isolated

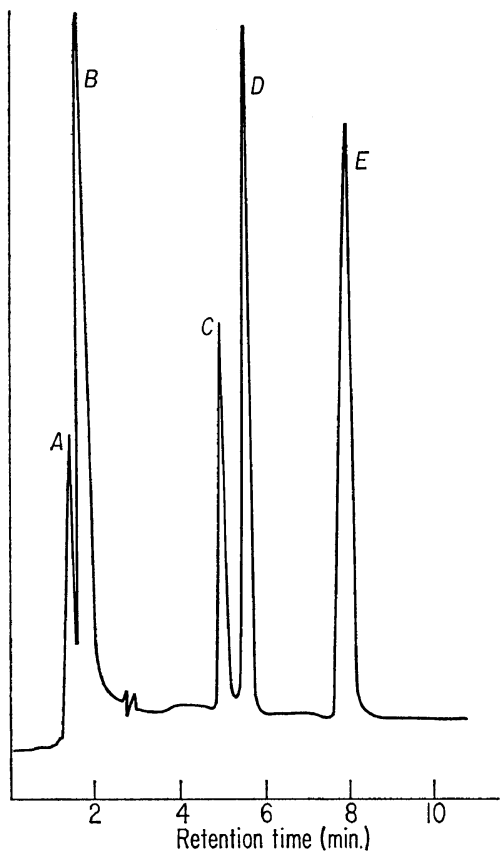

Figure 1. Typical gas chromatogram from an $\mathrm{Et}_{3} \mathrm{O}^{+} \mathrm{BF}_{4}-$ initiated reaction of oxetane at $70^{\circ} \mathrm{C}$.

according to the method of Rose. Peak D was the added $n$-tetradecane. Peak $\mathrm{C}$ was unexpected and was tentatively identified as cyclic trimer on the basis of its retention time and the molecular weight determined by mass chromatography (MW; Calcd 174, Found 174). The molecular weight found is consistent only with $\left(\mathrm{C}_{3} \mathrm{H}_{6} \mathrm{O}\right)_{3}$ and does not allow any feasible end groups. No evidence for any other cyclic oligomers were found either in the gas chromatograms or in a gel-permeation chromatogram of a product mixture at $100-\%$ conversion.

\section{With $\mathrm{BF}_{4}{ }^{-}$Counter-Ion}

Oxetane polymerizations with tetrafluoroborate counter-ion were obtained by initiating polymerization with $\mathrm{Et}_{3} \mathrm{O}^{+} \mathrm{BF}_{4}^{-}$in 1-mg increments $\left(5.3 \times 10^{-3} \mathrm{mmol}\right)$. As shown in Figure 2 polymerization rates, as indicated by the disappearance of monomer, were very rapid at the higher temperatures $\left(50-100^{\circ} \mathrm{C}\right)$. Also the reaction appeared to terminate equally rapidly at these temperatures. On the other hand reaction at $25^{\circ} \mathrm{C}$ or less resulted in a slower and much more sustained reaction. The amount of 


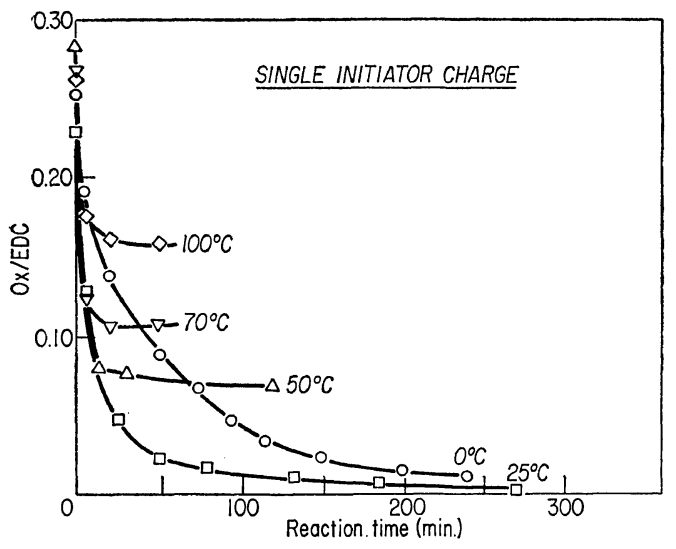

Figure 2. Disappearance of oxetane $(\mathrm{Ox})$ in $\mathrm{Et}_{3} \mathrm{O}^{+} \mathrm{BF}_{4}^{-}$initiated reactions of oxetane in ethylene dichloride (EDC) at various temperatures. $\mathrm{Ox} / \mathrm{EDC}$ is the ratio at time $t$ determined by gas chromatography.

initiator needed to react all of the oxetane monomer $(19 \mathrm{mmol})$ varied from $2 \mathrm{mg}$ at $0-25^{\circ} \mathrm{C}$ to $9 \mathrm{mg}$ at $100^{\circ} \mathrm{C}$, further showing the rapid termination reaction prevalent at the higher reaction temperatures.

The formation of polymer and of cyclic oligomer also was very rapid. Once products

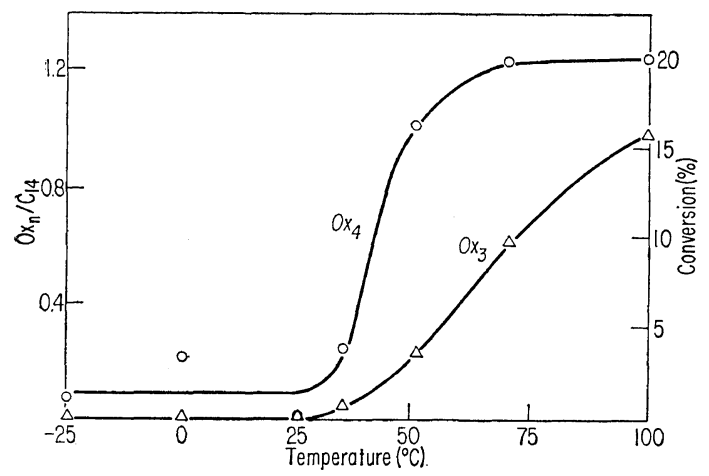

Figure 3. Effect of temperature on cyclic oligomer formation in reactions of oxetane initiated by $\mathrm{Et}_{3} \mathrm{O}^{+} \mathrm{BF}_{4}-$ in EDC. $\mathrm{Ox}_{4}, \mathrm{Ox}_{3}$, and $\mathrm{Ox}_{n} / \mathrm{C}_{14}$ are cyclic tetramer, cyclic trimer and the ratio of cyclic oligomer to the $n$-tetradecane internal standard, respectively. The \%-conversion on the right hand ordinate is the proportion of each cyclic oligomer formed at complete disappearance of monomer and is based on a calibration with cyclic tetramer.

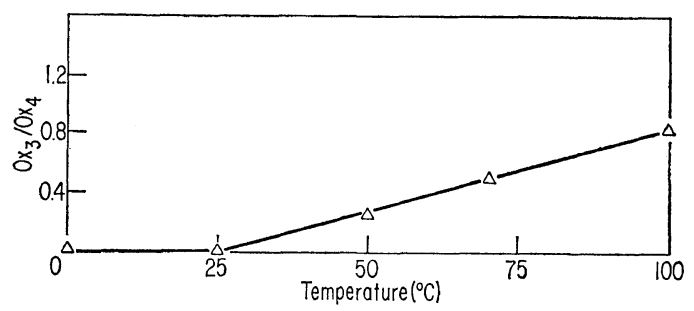

Figure 4. Effect of temperature on ratio of amounts of trimer to tetramer in reactions of oxetane initiated by $\mathrm{Et}_{3} \mathrm{O}^{+} \mathrm{BF}_{4}^{-}$in EDC. The symbols have the same meaning as in Figure 3.

formed, no changes in their distribution with time were observed by allowing the reaction mixture to be stirred at polymerization temperatures either before or after all the monomer had reacted. Furthermore, addition of initiator to the mixture after the complete disappearence of monomer gave no indication of even a slow depolymerization of polymer to cyclic oligomer or of a slow disappearance of cyclic oligomer to form polymer.

The amounts of the cyclic trimer and cyclic tetramer formed at complete conversion of monomer are shown in Figure 3 as a function of reaction temperature. The figure shows that polymerization temperature has an important effect. Oligomer formation was rather insignificant at temperatures below $50^{\circ} \mathrm{C}$ but increased with increasing temperature above $25^{\circ} \mathrm{C}$. Cyclic trimer formation increased more slowly with polymerization temperature than did cyclic tetramer formation. However, Figure 4 shows that above $25^{\circ} \mathrm{C}$, the amount of trimer relative to tetramer increased linearly with temperature of reaction.

With Ethyl Trifluoromethanesulfonate Initiator

Disappearance of monomer was very much slower with this initiator and termination was minimal. This is shown at $70^{\circ} \mathrm{C}$ in Figure 5 , which also shows that the rate of monomer disappearance is even slower when benzene solvent is used. Note that 5 times the usual initiator concentration was used in the experiments with EtOSO $\mathrm{CF}_{3}$ in benzene. As with triethyloxonium tetrafluoroborate, polymerizations using this initiator resulted in the simultaneous formation of significant quantities of 


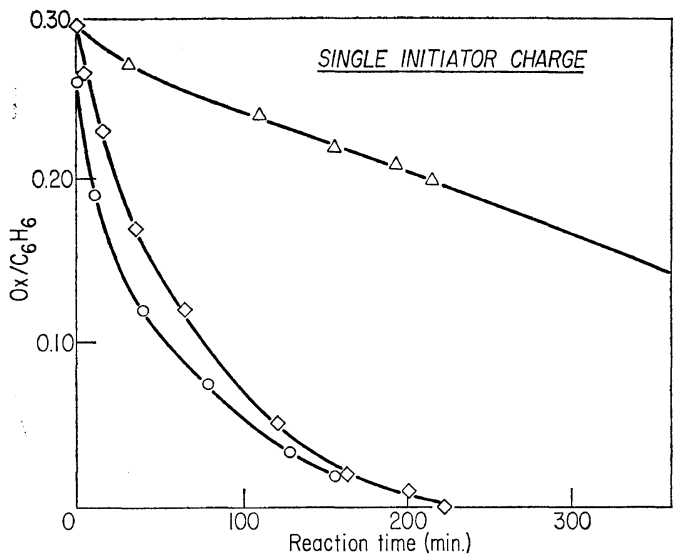

Figure 5. Disappearance of oxetane $(\mathrm{Ox})$ in reactions of oxetane in benzene at various temperatures. $\triangle$ and $\diamond$ are reactions initiated by $5 \times 10^{-3}$ $M \mathrm{EtOSO}_{2} \mathrm{CF}_{3}$ at 50 and $100^{\circ} \mathrm{C}$, respectively. is a reaction initiated by $1 \times 10^{-3} M \mathrm{Et}_{3} \mathrm{O}^{+} \mathrm{BF}_{4}^{-}$at $70^{\circ} \mathrm{C}$.

cyclic oligomers. However, the total amount of cyclic oligomer formed at complete conversion was somewhat less. Again both trimer and tetramer were observed, but in this case more trimer than tetramer was formed. The difference in the amount of trimer formed was even more striking when the less polar solvent, benzene was used. Use of $\mathrm{BF}_{4}^{-}$counter-ion in benzene solvent, shown for comparison in Table I, markedly reduced the amount of cyclic trimer formed.

We also studied cyclic oligomer formation in benzene solvent as a function of temperature with $\mathrm{EtOSO}_{2} \mathrm{CF}_{3}$ as initiator. (See Figure 6.) In

Table I. Cyclic oligomer formed during oxetane polymerization at $70^{\circ} \mathrm{C}$

\begin{tabular}{lcccc}
\hline Counter-ion & Solvent & $\mathrm{Ox}_{4} / \mathrm{C}_{14}{ }^{\mathrm{a}, \mathrm{b}}$ & $\mathrm{Ox}_{3} / \mathrm{C}_{14}{ }^{\mathrm{a}, \mathrm{b}}$ & $\mathrm{Ox}_{3} / \mathrm{Ox}_{4}{ }^{\mathrm{b}}$ \\
\hline $\mathrm{BF}_{4}^{-}$ & $\mathrm{EDC}$ & 1.23 & 0.62 & 0.50 \\
$\mathrm{CF}_{3} \mathrm{SO}_{3}^{-}$ & $\mathrm{EDC}$ & 0.18 & 0.33 & 1.83 \\
$\mathrm{BF}_{4}^{-}$ & $\mathrm{C}_{6} \mathrm{H}_{6}$ & 0.80 & 0.14 & 0.18 \\
$\mathrm{CF}_{3} \mathrm{SO}_{3}^{-}$ & $\mathrm{C}_{6} \mathrm{H}_{6}$ & 0.16 & 0.56 & 3.50 \\
\hline
\end{tabular}

a Relative amounts expressed as ratios to a constant amount of n-tetradecane as internal standard.

b The symbols have the same meaning as in Figure 3.

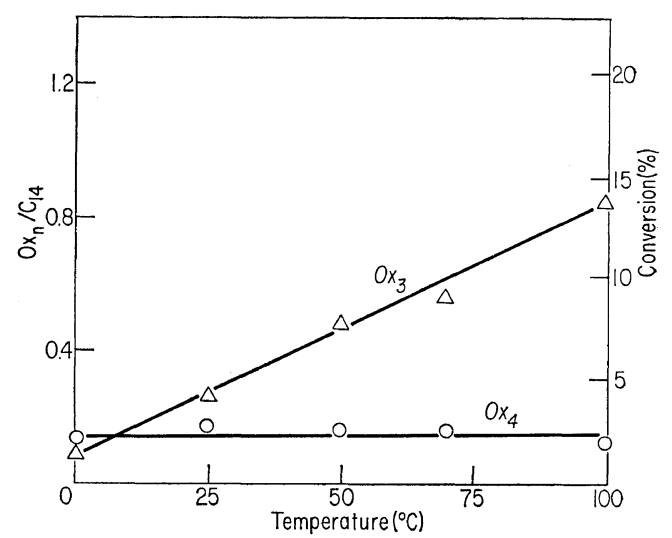

Figure 6. Effect of temperature on cyclic oligomer formation in reactions of oxetane initiated by EtOSO $\mathrm{CF}_{3}$ in benzene. The symbols have the same meaning as in Figure 3.

marked contrast to $\mathrm{BF}_{4}^{-}$(ethylene dichloride solvent), cyclic tetramer formation was essentially constant over the whole temperature range. On the other hand the relative amount of cyclic trimer that was forming appeared to increase linearly with temperature. Consequent$1 y$, at the higher temperatures considerably more cyclic trimer than cyclic tetramer was being. formed.

\section{With Other Counter-Ions}

The other counter-ions studied were $\mathrm{PF}_{6}{ }^{-}$, $\mathrm{SbF}_{6}{ }^{-}$, and $\mathrm{SbCl}_{6}{ }^{-}$. These were also introduced as their triethyloxonium salts. None of these

Table II. Effect of counter-ion on products of oxetane polymerization at $70^{\circ} \mathrm{C}$ in EDC

\begin{tabular}{lrrrc}
\hline Counter-ion ${ }^{\mathrm{a}}$ & $\begin{array}{c}\text { Initiator, } \\
\mathrm{mmol}\end{array}$ & $\mathrm{Ox}_{3} / \mathrm{C}_{14}{ }^{\mathrm{b}}$ & $\mathrm{Ox}_{4} / \mathrm{C}_{14}{ }^{\mathrm{b}}$ & $\mathrm{Ox}_{3} / \mathrm{Ox}_{4}{ }^{\mathrm{b}}$ \\
\hline $\mathrm{BF}_{4}{ }^{-}$ & 0.026 & 0.62 & 1.23 & 0.50 \\
$\mathrm{SbCl}_{6}{ }^{-}$ & 0.029 & $?^{\mathrm{c}}$ & 0.07 & $?$ \\
$\mathrm{PF}_{6}{ }^{-}$ & 0.024 & 0.07 & 0.11 & 0.64 \\
$\mathrm{SbF}_{6}{ }^{-}$ & 0.006 & 0.07 & 0.12 & 0.58 \\
$\mathrm{CF}_{3} \mathrm{SO}_{3}^{-}$ & 0.045 & 0.33 & 0.18 & 1.83 \\
\hline
\end{tabular}

a All counter-ions except $\mathrm{CF}_{3} \mathrm{SO}_{3}{ }^{-}$were obtained from triethyloxonium salts.

b The symbols have the same meaning as in Figure 3.

c The gas chromatographic plots indicate a small amount of $\mathrm{Ox}_{3}$ but the area was too small to measure with confidence. 
counter-ions resulted in the formation of a significant amount of cyclic oligomer. The same temperatures used with $\mathrm{BF}_{4}^{-}$and with $\mathrm{CF}_{3} \mathrm{SO}_{3}{ }^{-}$ were investigated but only a minimal conversion to cyclic oligomer resulted at all temperatures. However, both trimer and tetramer were always detected. Representative data for polymerizations carried out at $70^{\circ} \mathrm{C}$ are shown in Table II. Again, as in the case of $\mathrm{BF}_{4}^{-}$, we could not obtain evidence that cyclic oligomer formation was a backbiting or depolymerization process. Cyclic oligomer formed simultaneously with polymer and no more cyclic oligomer formed after the monomer was exhausted.

The relative differences noted among these counter-ions in the past were also evident here. ${ }^{11,14}$ Particularly evident was the very much smaller quantity of $\mathrm{SbF}_{6}^{-}$salt which was required to react all of the monomer. The effect could be interpreted as a longer effective lifetime of the active propagating species.

Using $\mathrm{SbF}_{6}^{-}$we showed that cyclic tetramer was stable toward initiator at room temperature and at $100^{\circ} \mathrm{C}$. That is, cyclic tetramer was not converted to polymer or anything else under typical polymerization conditions in the absence of monomer. However, we noted that initiator remained active in this experiment $1 \mathrm{hr}$ after the last addition of initiator at $100^{\circ} \mathrm{C}$ followed by $16 \mathrm{hr}$ at room temperature. Addition of monomer to this solution of tetramer resulted in immediate exothermic polymerization of the oxetane. There was no significant increase in the amount of cyclic tetramer, although cyclic trimer could be detected in very small amount. Since at higher temperatures the same initiator quickly looses its activity in the presence of monomer, a termination reaction involving monomer or polymer is indicated. Cyclic tetramer, as such, does not seem to be involved in the termination reaction.

\section{DISCUSSION}

\section{Effect of the $\mathrm{BF}_{4}^{-}$Counter-Ion (Comparison with Rose's Data) \\ Rose $^{1,15}$ used boron trifluoride as initiator in} his studies of oxetane polymerization. Water was presumed to be a necessary and present reactant in the initiation. He presumed that, as shown in eq 1 , his counter-ion was $\mathrm{BF}_{3} \mathrm{OH}^{-}$.

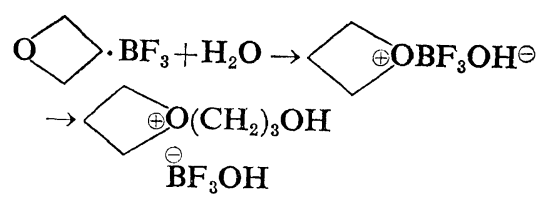

He charged monomer, solvent, and initiator at liquid nitrogen temperatures and then warmed the reaction mixture to the desired temperature, -80 to $100^{\circ} \mathrm{C}$. Rose reports yields of 4 to $50-\%$ cyclic tetramer, in addition to polymer. Higher percentages of tetramer were obtained from polymerizations at higher temperatures.

We preferred to use well-defined counter-ions and thus elected to use preformed trialkyloxonium ion salts as initiators. The reaction is shown in eq 2 . We ran only one experiment

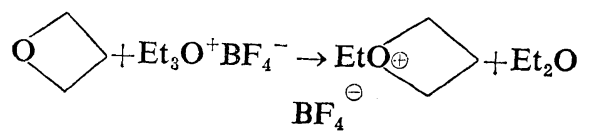

with $\mathrm{BF}_{3}$ to see if the results differed substantially from those obtained with $\mathrm{BF}_{4}^{-}$under our conditions. As shown in Table III they did not. We added initiator after the reaction mixture had reached the polymerization temperature.

Like Rose we observed that the amount of oligomer produced depended strongly on temperature. Oligomer formation was insignificant below $50^{\circ} \mathrm{C}$ and increased with increasing temperature above $50^{\circ} \mathrm{C}$. We observed two different cyclic oligomers, trimer and tetramer, in addition to polymer. Cyclic trimer formation increased more slowly with polymerization temperature than tetramer formation. Under our conditions the largest total conversion to cyclic oligomer was $35 \%$. We showed that, as expected from the kinetic study of Saegusa, et al. ${ }^{10}$ the very long polymerization times, 7 to 28 days, used by Rose were unnecessary.

Table III. Effect of initiator on products of oxetane polymerization at $50^{\circ} \mathrm{C}$ in $\mathrm{EDC}$

\begin{tabular}{lcccc}
\hline Initiator & $\mathrm{mmol}$ & $\mathrm{Ox}_{3} / \mathrm{C}_{14^{\mathrm{a}}}$ & $\mathrm{Ox}_{4} / \mathrm{C}_{14^{\mathrm{a}}}$ & $\mathrm{Ox}_{3} / \mathrm{Ox}_{4}{ }^{\mathrm{a}}$ \\
\hline $\mathrm{Et}_{3} \mathrm{O}^{+} \mathrm{BF}_{4}^{-}$ & 0.021 & 0.24 & 0.99 & 0.24 \\
$\mathrm{BF}_{3}$ & 0.024 & 0.20 & 0.65 & 0.31 \\
\hline
\end{tabular}

a The symbols have the same significance as in Figure 3. 


\section{P. Dreyfuss and M.P. Dreyfuss}

Disappearance of monomer was complete at $0^{\circ} \mathrm{C}$ in $5 \mathrm{hr}$ at comparable initiator concentrations. Longer polymerization times did not affect the amount of cyclic oligomer obtained. The reasons for the differences between Rose's and our results are not clear. We can only suggest that our method and our conditions are different.

Effect of Ethyl Trifluoromethanesulfonate Initiator

The initiation of cyclic ether polymerizations using the esters and anhydrides of the "superacids" $\mathrm{HOSO}_{2} \mathrm{~F}$ and $\mathrm{HOSO}_{2} \mathrm{CF}_{3}$ have been the subject of considerable recent investigation..$^{16-20}$ These recent studies have focused on the ionester equilibrium that often exists at the polymeric propagating site. (See eq 3.) Apparently,

$$
\begin{aligned}
& \left.\left.\mathrm{R} \in \mathrm{O}\left(\mathrm{CH}_{2}\right)_{4}\right]_{n} \mathrm{O}\right] \mathrm{SO}_{3} \mathrm{CF}_{3} \\
& \quad \leftrightharpoons \mathrm{R}\left[\mathrm{O}\left(\mathrm{CH}_{2}\right)_{4} \mathrm{~J}_{n} \mathrm{O}\left(\mathrm{CH}_{2}\right)_{4} \mathrm{OSO}_{2} \mathrm{CF}_{3}\right.
\end{aligned}
$$

in the case of oxiranes and oxetanes little if any oxonium ion is present and propagation occurs via the ester form. ${ }^{19,21}$ Thus we felt that the trifluoromethanesulfonate and fluorosulfonate "counter-ions" could offer more unique results with respect to cyclic oligomer formation in oxetane polymerization. Indeed our study with ethyl trifluoromethanesulfonate as initiator has substantiated this expectation.

Disappearance of monomer is very much slower using this initiator, consistent with the suggestion that propagation is via the ester form. Like the triethyloxonium tetrafluoroborate, this initiator resulted in the formation of a significant quantity of oligomer. The formation of cyclic trimer increased uniformly with increasing temperature. Strangely, however, cyclic tetramer formation appeared to be independent of temperature. A constant amount resulted over the temperature range studied. At this stage of our studies of cyclic oligomer formation we are unwilling to offer any explanation for this unusual difference in behavior between the oxonium ion and the superacid ester.

We must also note that when using ethyl trifluoromethanesulfonate as an initiator, especially at the higher polymerization temperatures studied, the $\beta$ elimination reaction ${ }^{22}$ shown in eq 4 may be introducing important complications but this was not investigated in the present study.

$$
\mathrm{RCH}_{2} \mathrm{CH}_{2} \mathrm{OSO}_{2} \mathrm{CF}_{3} \stackrel{\Delta}{\rightarrow} \mathrm{RCH}=\mathrm{CH}_{2}+\mathrm{HOSO}_{2} \mathrm{CF}_{3}
$$

\section{Effect of Other Counter-Ions}

$\mathrm{BF}_{4}{ }^{-}$is known to be among the less stable and less suitable counter-ions for use in cyclic ether polymerizations. ${ }^{11,14}$ The trifluoromethanesulfonate leads to an ester system. We expected to see some differences using larger and more stable counter-ions like $\mathrm{PF}_{6}{ }^{-}, \mathrm{SbF}_{6}{ }^{-}$, and possibly $\mathrm{SbCl}_{6}{ }^{-}$. In fact, there was a large difference. Even at the highest temperatures studied formation of cyclic oligomers was very small. Further work is needed to establish why these counterions behave so differently with respect to cyclic oligomer formation in oxetane polymerizations.

\section{CONCLUSIONS}

The results of our initial study of factors affecting cyclic oligomer formation allow a number of conclusions to be stated. Polymerization of oxetane leads to polymer, cyclic trimer and cyclic tetramer. No higher cyclic oligomers were observed. Polymer was not converted to cyclic oligomer by adding initiator to reaction mixtures after complete disappearance of monomer. Cyclic oligomers formed only when initiator was added to a mixture containing monomer. Cyclic tetramer was not converted to polymer under polymerization conditions. Thus, cyclic oligomer formation appears to be a concurrent process with polymerization. It does not appear to be a result of a backbiting reaction with depropagation as in, for example, the depolymerization in the reversible tetrahydrofuran polymerization. The amount and type of cyclic oligomer obtained is very dependent on counter-ion, temperature and solvent. Other variables not yet studied, such as monomer concentration, are probably also important. These results strongly indicate that it is possible to exercise a considerable degree of control in these reactions. It should be possible to develop conditions where cyclic oligomers are the primary product of polymerization and even 


\section{Cyclic Oligomers in Oxetane Polymerization}

where the ring size is predetermined. This study is continuing with oxetane and other cyclic ethers.

\section{REFERENCES}

1. J. B. Rose, J. Chem. Soc., 542 (1956).

2. R. J. Kern, J. Org. Chem., 33, 388 (1968).

3. A. M. Eastham, in "The Chemistry of Cationic Polymerization," P. H. Plesch, Ed., Macmillan, New York, N.Y., 1963, Chapter 10.

4. K. C. Frisch and S. L. Reegen, Eds., "RingOpening Polymerization," Marcel Dekker, New York, N.Y., 1969.

5. P. Dreyfuss and M. P. Dreyfuss, Advan. Polym. Sci., 4, 528 (1967).

6. Ya. I. Estrin and S. G. Entelis, Polym. Sci., USSR, 10, 3006 (1968); ibid., 11, 1286 (1969); ibid., 13, 1862 (1971).

7. C. J. Pedersen and H. K. Frensdorf, Angew. Chem., Internat. Edn., 11, 16 (1972).

8. J. Dale and coworkers in "Heart Cut," L. A. Pilato, J. McGrath, and W. T. Reichle, Chem. Tech., 5, 3 (1975).

9. J. Cooper and P. H. Plesch, Chem. Commun., 1017 (1974).
10. T. Saegusa, J. Hashimoto, and S. Matsumoto, Macromolecules, 4, 1 (1971).

11. P. Dreyfuss and M. P. Dreyfuss, Advan. Chem., 91, 335 (1969).

12. M. P. Dreyfuss, U.S. Patent 3585227 (1970).

13. S. Kobayashi, H. Danda, and T. Saegusa, Bull. Chem. Soc. Japan, 46, 3214 (1973).

14. F. R. Jones and P. H. Plesch, Chem. Commun., 1231 (1969).

15. J. B. Rose, J. Chem. Soc., 546 (1956).

16. S. Smith and A. J. Hubin, J. Macromol. Sci.Chem., A7, 1399 (1973).

17. K. Matyjaszewski, P. Kubisa, and S. Penczek, J. Polym. Sci., Polym. Chem. Ed., 12, 1333 (1974).

18. K. Matyjaszewski and S. Penczek, ibid., 12, 1905 (1974).

19. T. Saegusa and S. Kobayashi, "Polyethers," ASC Symposium Series, No. 6, American Chemical Society, 1975, p 150.

20. T. K. Wu and G. Pruckmayr, Macromolecules, 8, 77 (1975).

21. S. Kobayashi, H. Danda, and T. Saegusa, Bull. Chem. Soc. Japan, 47, 2699 (1974).

22. T. Gramstad and R. N. Haszeldine, J. Chem. Soc., 4069 (1957). 